\title{
CARING FOR OUR PATIENTS FACT OR LEGEND
}

\section{P. Harrison}

\section{TECHNOLOGY}

With 1980 well into its stride it must be becoming more and more evident that what most people understand by the word "technology" is going to play an ever-increasing role in everyday living and influence to an even greater extent the quality of life. It does not really matter what area one thinks of - agriculture, transport, education, mining, commerce and industry and our own specific area of health service, nursing, technology is integral to our continued existence.

Technology has to do with machines, engineering skills, science. The fact that today we refer to our nursing studies as Nursing Science, our departments of universities as Departments of Nursing Science, some of our degrees as B.Sc. Nursing, bears out this world-wide trend - as if the word 'science' per se holds some sort of magical guarantee of academic respectability or acceptability.

The whole idea of technology is linked with improved productivity. More housing, more hospital beds, more classrooms, more food production to cope with the Tyranny of Numbers (a rather harsh description of the population explosion!). Just in the area of hospital design and management and equipment, consider for a moment the Tygerberg Hospital or the new Johannesburg Hospital. The previous 'Gen' in its heyday was considered the ultimate in hospital design and equipment - a mere 30 years ago? One's mind boggles at what sort of institution will replace the new "Jo'burg Gen" in, say, 40 years time. The chief matron of that new hospital of the year 2019 is today a young 18-yearold student nurse somewhere in South Africa, being taught by the likes of us, in today's environment.

Computer print-outs, once a tool for the select few and regarded with awe and suspicion by the uninitiated, are today taken as a matter of course by all sorts of persons - even schoolchildren have inter-school competitions on marketing and economic predictions using print-outs as one of their source materials. Children in primary grades use calculators with all the aplomb and poise of seasoned actuaries - sub-grades in schools do not do arithmetic anymore, but "new Maths". This is the sort of background our nursing recruits and patients will come from. The big question is, how is this going to affect the essence of the 'caring' component of nursing? Can technological expertise include 'caring' or are these two concepts incompatible and even antagonistic to each other?

The obvious area that springs 10 mind is the intensive care unil. Here medical and nursing technology is work- ing at top pressure - but note, the description is intensive CARE not intensive SUPPORT or intensive THERAPY or intensive TREATMENT. Was this accidental or deliberate? I do not think it was the former. The idea of caring is entrenched in this highly specialised area as an integral part of the whole experience both for nursing, medical and paramedical staff and the patient and his relatives.

As a result of technology and the knowledge explosion flowing from it, sick persons are treated with more certainty and confidence, diagnoses are arrived at quickly and accurately, once certain killers like laryngeal diphtheria or T.B. meningitis are now manageable. Does a technological approach affect the less acute areas of hospitals in a negative manner? Let us consider the geriatric unit. Patients are slow-moving, confused, apprehensive of all the 'gadgets' in their environment, accustomed to a more leisurely way of life only wanting nursing staff to take time to talk to them, handle them in an unrushed personalised way, in fact to care for them in a way an 80-year-old can cope with. Aids have undoubtedly made their mobility and rehabilitation a little easier - special chairs, walking aids, hearing aids, eating utensils, etc. But that indefinable attitude of mind of nursing personnel is so often lacking - the ability to demonstrate care by the tone of voice, the touch of hand, the expression of face. These are the tools we have within ourselves, to cultivate, refine and use in an increasingly effective way. It requires creative imagination on the part of nurse teachers to get young students to be aware of their potential to care for as well as cure their patients and it is so often in the situation where curing is no longer a possibility that caring comes into its own. If only nurses would realise that it is in these profoundly soul-stirring moments that they achieve the whole purpose for which they exist and that caring for our patients will always be very much a FACT and never become a Legend, referred to in future History of Nursing notes as a sort of phase through which nursing passed in the 20th century.

We who call ourselves educators (remember, to educate stems from the Latin word to lead forth) must be the living examples to our students of people who care; in our interpersonal relations with them, the students, our colleagues in hospitals and clinics, our attitudes to patients and their relatives.

That well-worn expression - 'Do-unto-others-asyou-would-have-them-do-unto-you' - has never been more needed in our day-to-day living. It is our responsibility as educators of nurses to breathe life into these words and make them a reality. 